\title{
Radiofrequency ablation vs. surgical resection for resectable hepatocellular carcinoma: A systematic review and meta-analysis
}

\author{
JIA-KAI LI ${ }^{1 *}$, XIAO-HUI LIU ${ }^{2 *}$, HONG CUI ${ }^{2}$ and XIN-HUI XIE ${ }^{3}$ \\ ${ }^{1}$ Department of Radiology, Hainan Hospital of PLA General Hospital, Sanya, Hainan 572013; \\ ${ }^{2}$ Department of Medical Psychology, Chinese PLA General Hospital and Medical School PLA, Beijing 100853; \\ ${ }^{3}$ Department of Medical Psychology, Anhui Medical University, Hefei, Anhui 230032, P.R. China
}

Received February 13, 2019; Accepted August 21, 2019

DOI: $10.3892 / \mathrm{mco} .2019 .1941$

\begin{abstract}
The treatment of hepatocellular carcinoma (HCC) is a significant challenge. Although radiofrequency ablation (RFA) has emerged as a popular therapeutic option for patients with resectable $\mathrm{HCC}$, whether it can achieve comparable survival outcomes compared with surgical resection (RES) remains unclear. The aim of the present study was to conduct a meta-analysis to assess the survival outcomes of RFA vs. RES in patients with early resectable HCC tumors. A Medline, Embase, and Cochrane Library search was performed for data published between January 2000 and February 2018. A meta-analysis of the efficacy of RFA compared with RES for HCC was subsequently performed, with particular emphasis on overall survival and disease-free survival (DFS) rates. Pooled odds ratios (ORs) with 95\% confidence intervals (CIs) were calculated using the random-effects model. In the present study, a total of 13,147 patients with $\mathrm{HCC}$ were included; of which, 6,727 were treated with RFA and 6,420 were treated with RES. The overall survival rates $\left(\mathrm{OR}_{1-\text { year }}, 0.757\right.$, 95\% CI, 0.578-0.989; OR $_{3 \text {-year }}, 0.530,95 \%$ CI, 0.401-0.700; $\left.\mathrm{OR}_{5 \text {-year }}, 0.566,95 \% \mathrm{CI}, 0.423-0.758\right)$ and the DRS rates $\left(\mathrm{OR}_{1 \text {-year }}, 0.569,95 \% \mathrm{CI}, 0.456-0.711 ; \mathrm{OR}_{3 \text {-year }}, 0.418\right.$, 95\% CI, 0.267-0.653; $\mathrm{OR}_{5 \text {-year }}, 0.374,95 \%$ CI, 0.231-0.606) of RES were significantly higher than those of RFA. The results indicate that RES is superior to RFA for promoting the survival of selected patients with resectable HCC. However, future randomized controlled trials are required to investigate the specific relevance of these modalities in the treatment of HCC.
\end{abstract}

Correspondence to: Dr Jia-Kai Li, Department of Radiology, Hainan Hospital of PLA General Hospital, 80 Jianglin Road, Sanya, Hainan 572013, P.R. China

E-mail: lijiakai2004@aliyun.com; 13521804788@163.com

${ }^{*}$ Contributed equally

Key words: hepatocellular carcinoma, radiofrequency ablation, resection, meta-analysis

\section{Introduction}

Hepatocellular carcinoma (HCC) is the fifth most common cancer and the third leading cause of cancer-related death worldwide (1). HCC is more common in Asia and Africa compared with western countries $(2,3)$. However, incidence rates of HCC in western countries have been gradually increasing in recent years $(3,4)$.

$\mathrm{HCC}$ is treated by surgical resection (RES), radiofrequency ablation (RFA), liver transplantation, as well as other methods. Currently, the most effective treatment option for patients with HCC is a liver transplant; however, due to the lack of available donors, this method is not widely used (5). As a consequence, RES is considered to be the most popular treatment strategy for patients with resectable tumors and good liver function (a Child-Pugh score of A or B) (6-8). However, only 9-29\% of patients with $\mathrm{HCC}$ are able to tolerate surgery, either due to poor hepatic reserves as a result of potential chronic liver disease, or due to the multifocal distribution of tumor nodules (9-16).

RFA has been demonstrated to be safe and effective for the treatment of patients with tumors $<3 \mathrm{~cm}$ in size. In addition, RFA is associated with lower mortality rates and shorter hospital stays (17-20). However, only a small number of randomized controlled trials (RCTs) comparing the effectiveness of RFA and RES have been performed (21-23), and the results are contradictory. In addition, the value of these RCTs is limited due to a small number of samples analyzed and the wide confidence intervals (CIs). A number of studies have concluded that RFA is as effective as RES in the treatment of solitary and small HCC tumors (21,24-29). Livraghi et al (29) even regarded RFA as the preferable treatment for small, resectable HCC tumors (tumor size, $\leq 2 \mathrm{~cm}$ ). By contrast, other studies arrived at the opposite conclusion $(18,30,31)$. RES may improve long-term disease-free survival (DFS) rates, and potentially increase overall survival (OS) rates, when compared with RFA in a subgroup of patients with single $\mathrm{HCC}$ tumors $>2 \mathrm{~cm}$ in size and with Child-Pugh class A liver function scores. The conflicting results of these previous studies are primarily considered to be related to the relatively small sample sizes. Similarly, previously published reviews and meta-analyses present contradictory results. A number of these studies concluded that no significant difference in death rates following treatment of HCC using RES and RFA 
was observed, if disease recurrence following RFA was detected in a timely manner and effectively treated $(32,33)$. However, the opposite conclusions have been drawn in other review studies $(17,34)$. In these studies, it was argued that RFA did not decrease the number of overall recurrences and had no effect on patient survival when compared with RES in a selected group of patients. In addition, RES was superior to RFA with regards to overall or recurrence-free survival. The contradictory results from these studies may be due to inconsistencies between the subjects recruited, therapeutic techniques employed and the evaluation criteria. However, a recent systematic review concluded that the indication for RFA as a primary treatment for patients with early stage HCC that are eligible for RES is unclear, and additional well-designed RCTs are required (35). Ultimately, due to the small number of RCTs performed thus far, the heterogeneity of different studies and the inherent limitations of meta-analyses, it is currently unclear whether RFA or RES is more effective for the treatment of patients with resectable HCC. Strong evidence is required to compare RFA and RES treatment strategies. Therefore, the aim of the present study was to conduct a meta-analysis of 13,147 patients with HCC to compare the therapeutic effects of RFA and RES.

\section{Materials and methods}

Literature search. A Medline, Embase, and Cochrane Library search was performed for data published between January 2000 and February 2018. The following keywords were used as search criteria: 'RFA, radio-frequency, radio frequency or RFA' AND 'RES or hepatectomy' AND 'liver or hepatic or HCC' with no language restrictions. Additional studies were identified by manual searching of the references by two reviewers.

Study selection criteria. The following selection criteria for studies were applied: i) Those that included patients with no previous treatment for $\mathrm{HCC}$; ii) those that included patients suitable for treatment with either RES or RFA (based on the Milan Criteria) and with liver function Child-Pugh scores of grade A or B; iii) results for at least one of the outcome measures, including the 1-, 3- and 5-year OS or DFS rates; and iv) studies published in peer-reviewed journals.

Data extraction. Data was extracted independently by two observers and cross-checked to reach a consensus. The following parameters were recorded: Author; journal; date of publication; geographical region; number of patients; age; sex; liver function; tumor size; Child-Pugh class; number of tumors; death rates; 1-, 3- and 5-year OS rates; and 1-, 3- and 5 -year DFS rates. The primary authors were contacted to retrieve further information where necessary.

Quality assessment. The quality of the RCTs were assessed using the Jadad Scoring system (36) and the quality of observational studies was assessed using the Newcastle-Ottawa Scale (NOS) (37). Although the majority of studies included were observational studies, these studies had high NOS scores $\left(\geq 5^{*}\right)$ and were found to be important for directing clinical work.

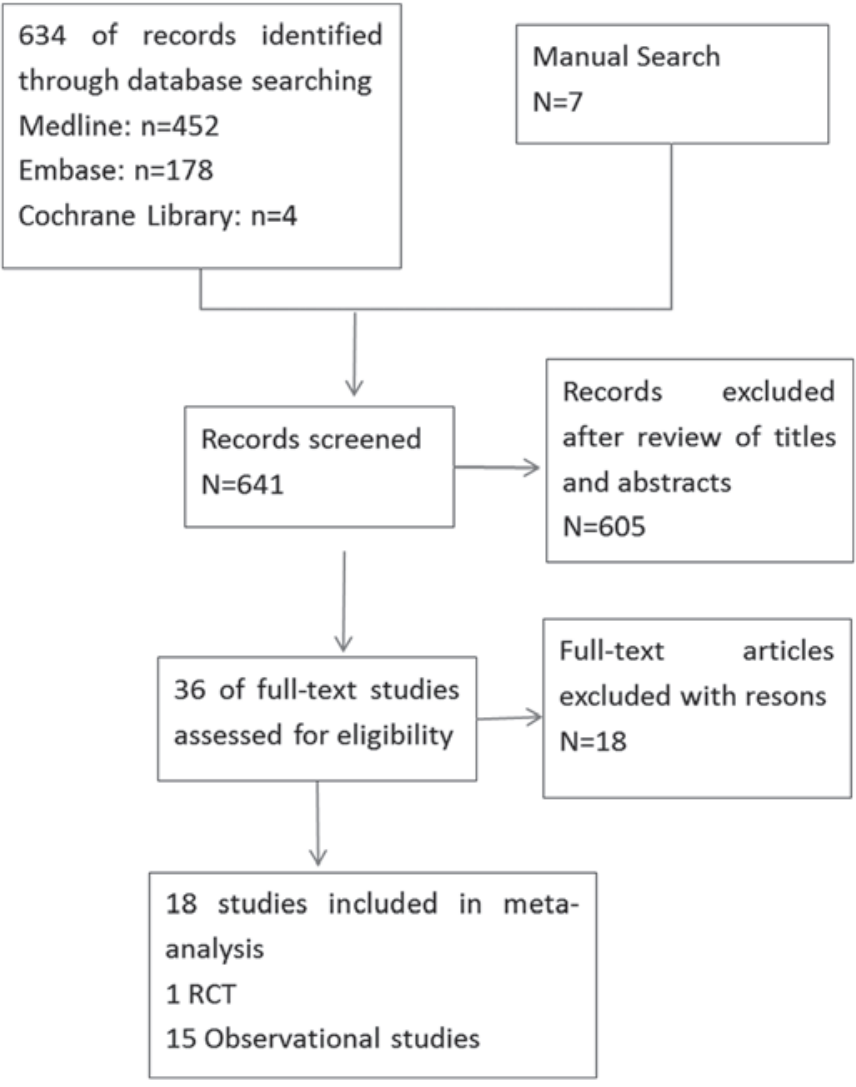

Figure 1. Summary diagram of the studies included in the analysis of the current study.

Data analysis. A meta-analysis was performed according to the recommendations of the Preferred Reporting Items for Systematic Reviews and Meta-Analyses guidelines. The analysis was conducted using the STATA 12.0 statistical software and Review Manager Version 5.1. For statistical analysis of the pooled odds ratio (OR) for categorical variables, which correspond to the odds of an event occurring in the treatment group (RFA), compared to the control group (RES) was used. An OR of $>1$ indicates that the probability of an outcome is more likely to occur in the treatment group, and is considered statistically significant when $\mathrm{P}<0.05$ and the $95 \%$ CI does not include the value 1 . The Mantel-Haenszel method was used to combine the ORs for outcomes of interest to the present study. A random-effects model, that is more robust in terms of anticipated heterogeneity in patient and hospital-related risk factors, was used for the meta-analysis due to the considerable clinical heterogeneity of surgical procedures and study designs $(38,39)$. However, the statistical heterogeneity in each meta-analysis was assessed using the $\tau^{2}, \chi^{2}$ and $\mathrm{I}^{2}$ statistics parameters. Heterogeneity was regarded as significant if $\tau^{2}$ was $>0$ and if either the P-value of $\chi^{2}$ analysis was $<0.10$ or the $\mathrm{I}^{2}$ vale was $>50 \%$. Subgroup analyses included: i) A mean tumor size of $\leq 3 \mathrm{~cm}$ and (ii) a mean tumor size of $>3 \mathrm{~cm}$.

\section{Results}

Description of the studies. Out of the 13,147 patients with HCC across 25 studies included in the current study, 6,727 were 


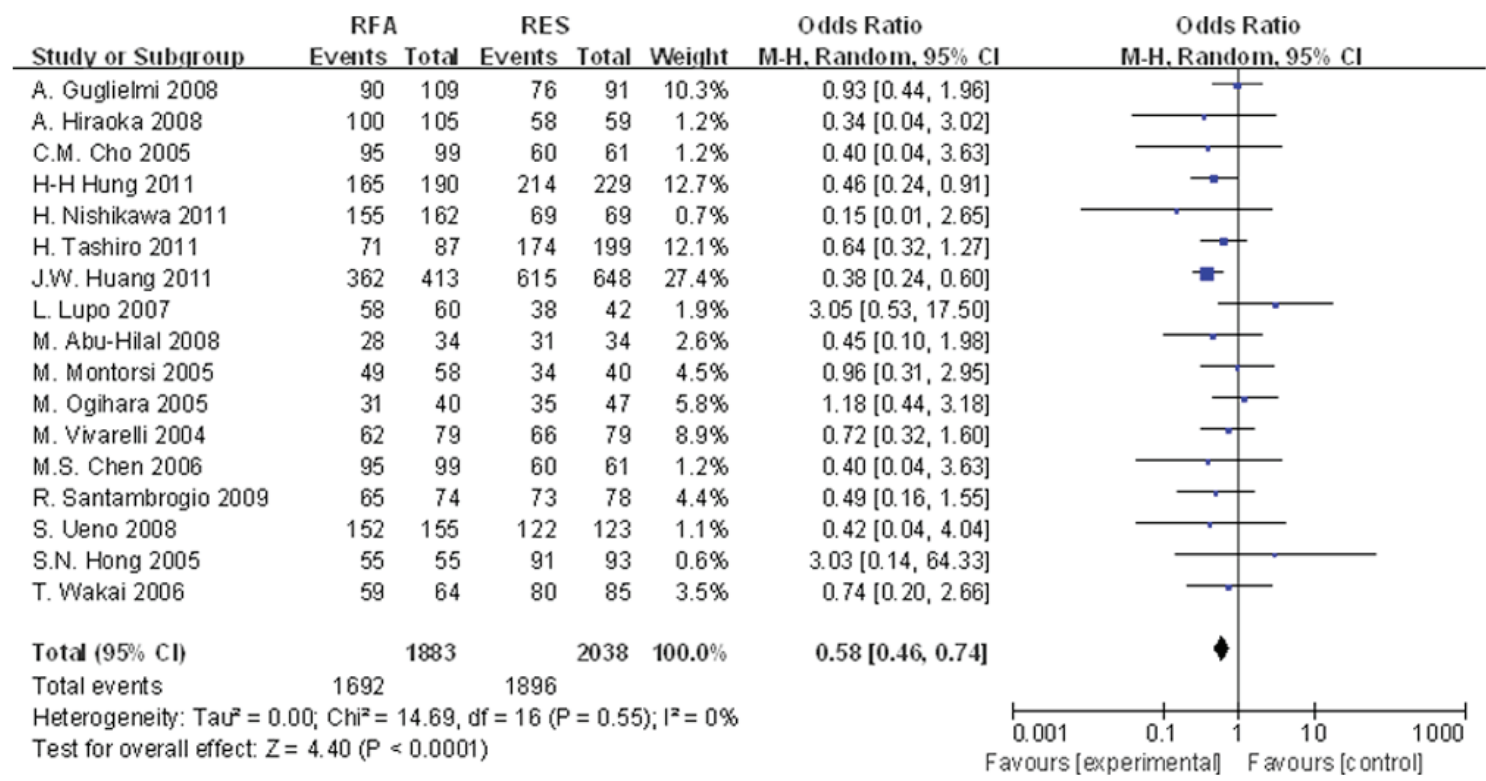

Figure 2. Significant differences in the 1-year OS rates between the two groups were observed (OR, 0.757; 95\% CI, 0.578-0.989; P=0.042). OS, overall survival; OR, odds ratio; $\mathrm{CI}$, confidence interval.

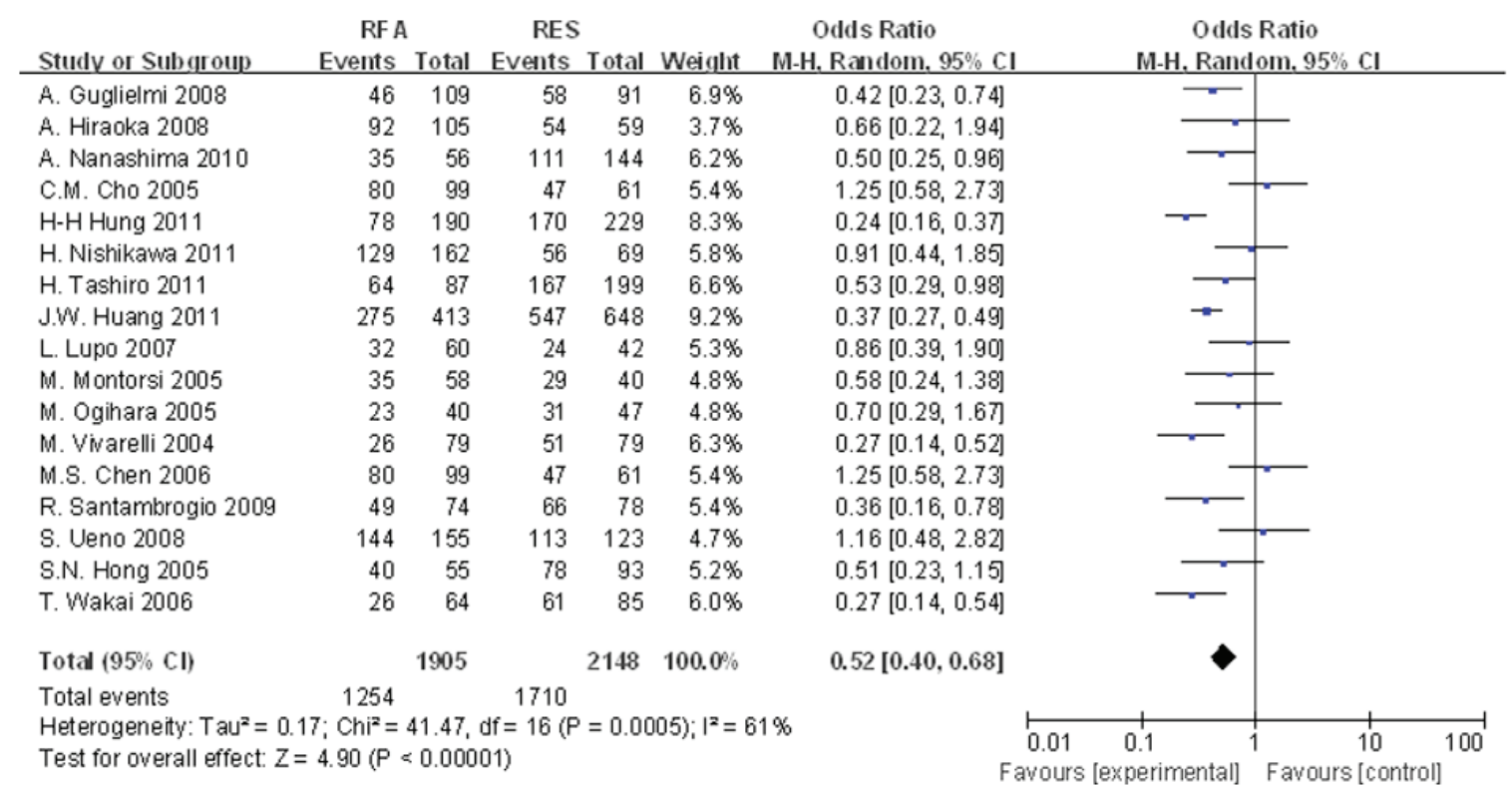

Figure 3. Significant differences in the 3-year OS rates between the two groups were observed (OR, 0.530; 95\% CI, 0.401-0.700; P<0.001). OS, overall survival; OR, odds ratio; CI, confidence interval.

allocated to the RFA group and 6,420 were allocated to the RES group in order to evaluate the therapeutic effects of these treatment modalities. The selected studies included three RCTs and 20 observational comparative studies. The overlap in time of patients was detected in two trials $(22,40)$ and the non-randomly controlled trial was excluded (40). Two trials $(21,41)$ were thought to have overlapping data, as they were conducted in the same center (21); one was an RCT that recruited patients with solitary HCC tumors $\leq 5 \mathrm{~cm}$ in diameter between November 1999 and June 2004, while the other (41) was a retrospective study that analyzed patient data collected between December 2003 to December 2008. As a result, only the RCT was included in the current study (Fig. 1). Data from patients presenting with a mean tumor size of $<3$ and $>3 \mathrm{~cm}$ were divided into the subgroup analysis whenever the author presented them independently in the study.

\section{Outcome measures}

$O S$ rates. The meta-analysis results demonstrated a significant difference in the 1-, 3- and 5-year OS rates between the two groups. The OR of 1-year OS rates of the two groups was 0.757 (95\% CI, 0.578-0.989; $\mathrm{P}=0.042$; Fig. 2). For the 3 -year OS rates, the OR of the two groups was 0.530 (95\% CI, 0.401-0.700; P<0.001; Fig. 3). Finally, the OR of 5-year OS rates in the two groups was 0.566 (95\% CI, 0.423-0.758; P=0.001; Fig. 4). 


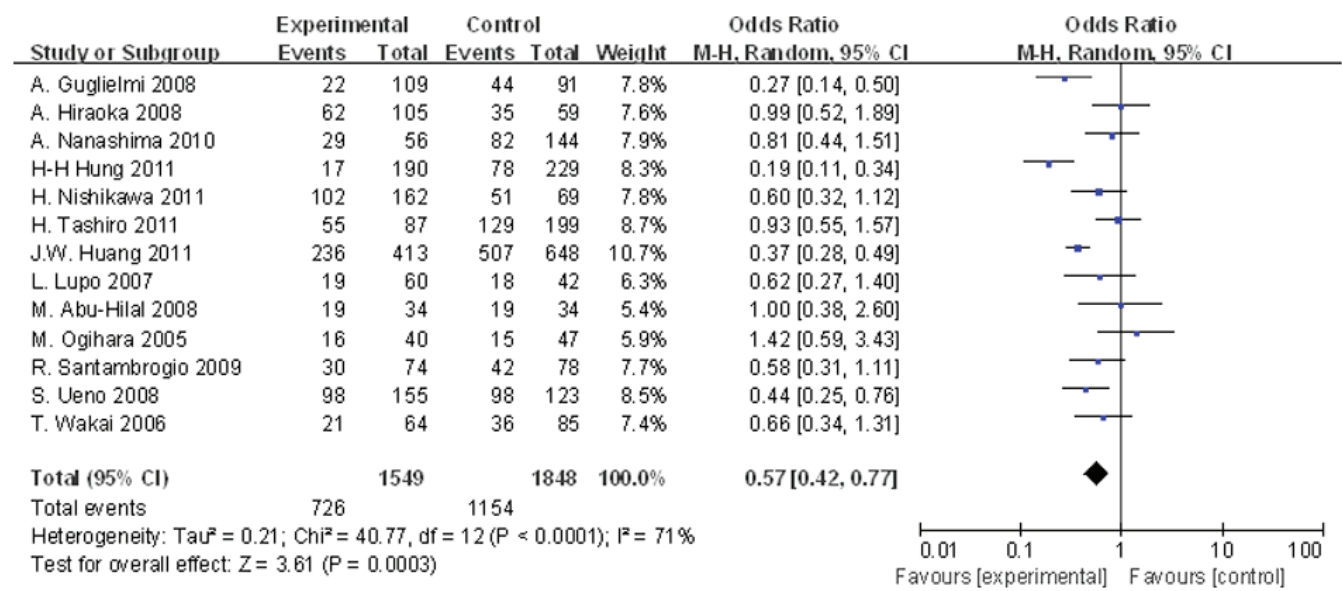

Figure 4. Significant differences in the 5 -year OS rates between the two groups were observed (OR, 0.566; 95\% CI, 0.423-0.758; $\mathrm{P}=0.001)$. OS, overall survival; OR, odds ratio; $\mathrm{CI}$, confidence interval.

\begin{tabular}{|c|c|c|c|c|c|c|c|c|c|c|}
\hline Studv or Subaroup & $\begin{array}{r}\text { RF A } \\
\text { Events }\end{array}$ & Total & $\begin{array}{l}\text { RES } \\
\text { Events }\end{array}$ & Total & Weight & $\begin{array}{l}\text { Odds Ratio } \\
\text { M-H. Random. } 95 \% \mathrm{Cl}\end{array}$ & & \multicolumn{2}{|c|}{$\begin{array}{c}\text { Odds Ratio } \\
\text { M-H. Random. } 95 \% \mathrm{Cl}\end{array}$} & \\
\hline A. Guglielmi 2008 & 53 & 89 & 76 & 91 & $7.4 \%$ & $0.29[0.14,0.58]$ & & & & \\
\hline A. Hiraoka 2008 & 92 & 105 & 54 & 59 & $3.9 \%$ & $0.66[0.22,1.94]$ & & & & \\
\hline A. Nanashima 2010 & 40 & 56 & 104 & 144 & $7.6 \%$ & $0.96[0.48,1.91]$ & & & & \\
\hline H-H Hung 2011 & 108 & 190 & 176 & 229 & $12.5 \%$ & $0.40[0.26,0.60]$ & & $\varpi$ & & \\
\hline H. Nishikawa 2011 & 133 & 162 & 59 & 69 & $6.4 \%$ & $0.78[0.36,1.70]$ & & & & \\
\hline H. Tashiro 2011 & 53 & 87 & 133 & 199 & $10.3 \%$ & $0.77[0.46,1.30]$ & & $\rightarrow$ & & \\
\hline J.W. Huang 2011 & 304 & 413 & 521 & 648 & $15.6 \%$ & $0.68[0.51,0.91]$ & & $\rightarrow$ & & \\
\hline L. Lupo 2007 & 41 & 60 & 31 & 42 & $5.4 \%$ & $0.77[0.32,1.84]$ & & & & \\
\hline M. Abu-Hilal 2008 & 14 & 34 & 26 & 34 & $4.1 \%$ & $0.22[0.08,0.61]$ & & & & \\
\hline M. Ogihara 2005 & 25 & 40 & 30 & 47 & $5.4 \%$ & $0.94[0.39,2.26]$ & & & & \\
\hline M. Vwarelli 2004 & 47 & 79 & 62 & 79 & $7.4 \%$ & $0.40[0.20,0.81]$ & & & & \\
\hline M.S. Chen 2006 & 85 & 99 & 53 & 61 & $4.9 \%$ & $0.92[0.36,2.33]$ & & & & \\
\hline S. Ueno 2008 & 121 & 155 & 98 & 123 & $9.2 \%$ & $0.91[0.51,1.62]$ & & & & \\
\hline Total $(95 \% \mathrm{Cl})$ & & 1569 & & 1825 & $100.0 \%$ & $0.61[0.48,0.78]$ & & 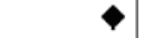 & & \\
\hline Total events & 1116 & & 1423 & & & & & & & \\
\hline $\begin{array}{l}\text { Heterogeneity: } \mathrm{Tau}^{2}= \\
\text { Test for overall effect }\end{array}$ & $\begin{array}{l}0.07 ; \mathrm{Chi}^{2} \\
=4.05(\mathrm{~F}\end{array}$ & $\begin{array}{l}=20.6 \\
P<0.0\end{array}$ & $d f=12$ & $(\mathrm{P}=$ & $1.06) ; 1^{2}=$ & & $\begin{array}{l}0.01 \\
\text { avours }\end{array}$ & 0.11 & $1 \frac{10}{\text { Favours [col }}$ & 100 \\
\hline
\end{tabular}

Figure 5. Significant differences in the 1-year DFS rates between the two groups were observed (OR, 0.569; 95\% CI, 0.456-0.711; P<0.001). DFS, disease-free survival; OR, odds ratio; CI, confidence interval.

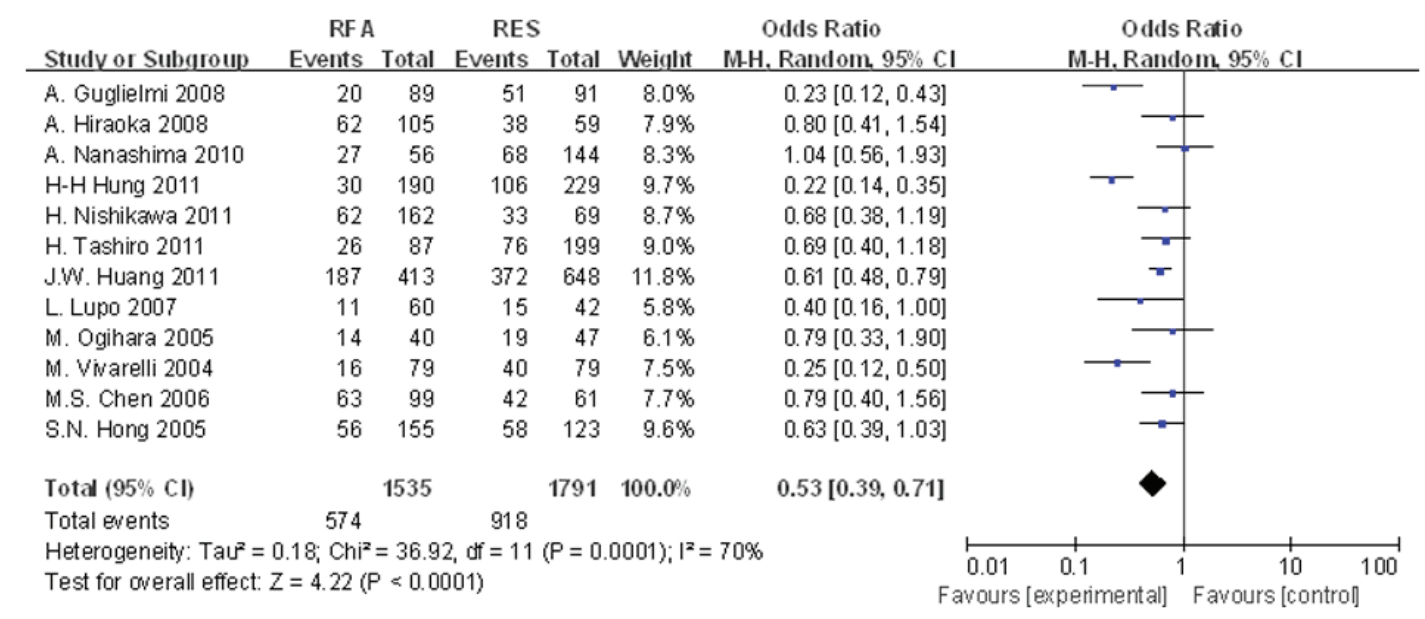

Figure 6. Significant differences in the 3-year DFS rates between the two groups were observed (OR, 0.418; 95\% CI, 0.267-0.653; P<0.001). DFS, disease-free survival; OR, odds ratio; $\mathrm{CI}$, confidence interval.

DFS rates. The results of the meta-analysis demonstrated a significant difference in the 1-, 3- and 5-year DFS rates between the two groups. As indicated in Fig. 5, the OR of 1-year DFS in the two groups was 0.569 (95\% CI, 0.456-0.711; $\mathrm{P}<0.001)$. The 


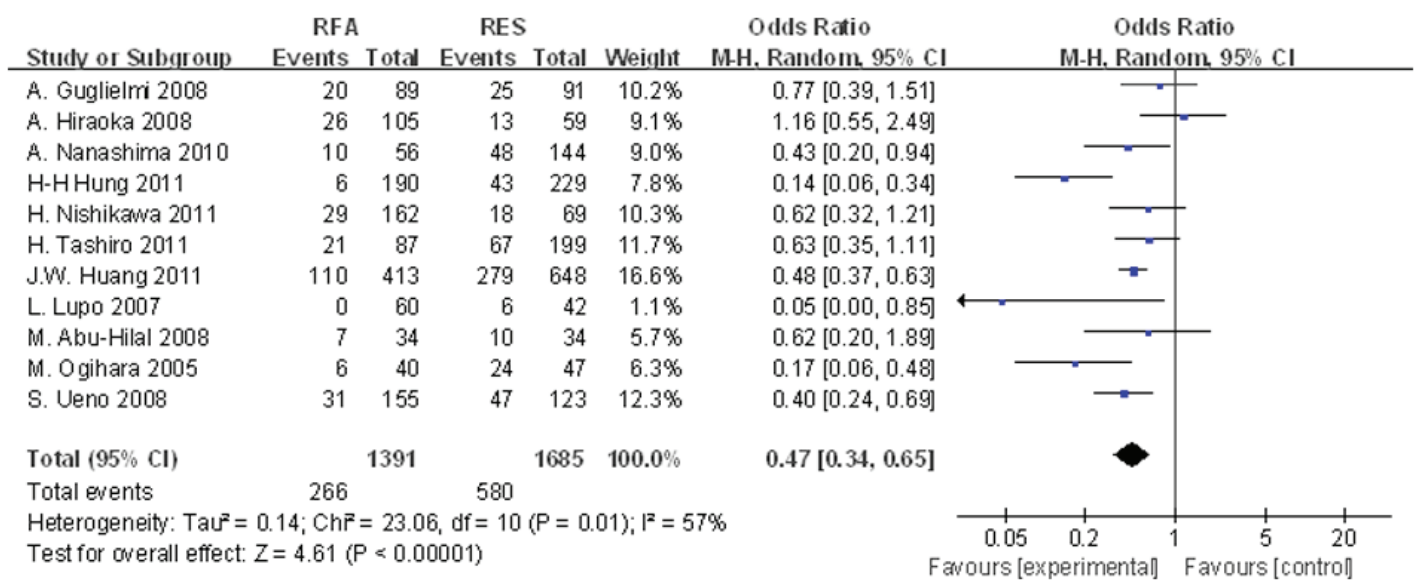

Figure 7. Significant differences in the 5-year DFS rates between the two groups were observed (OR, 0.374; 95\% CI, 0.231-0.606; P<0.001). DFS, disease-free survival; OR, odds ratio; CI, confidence interval.

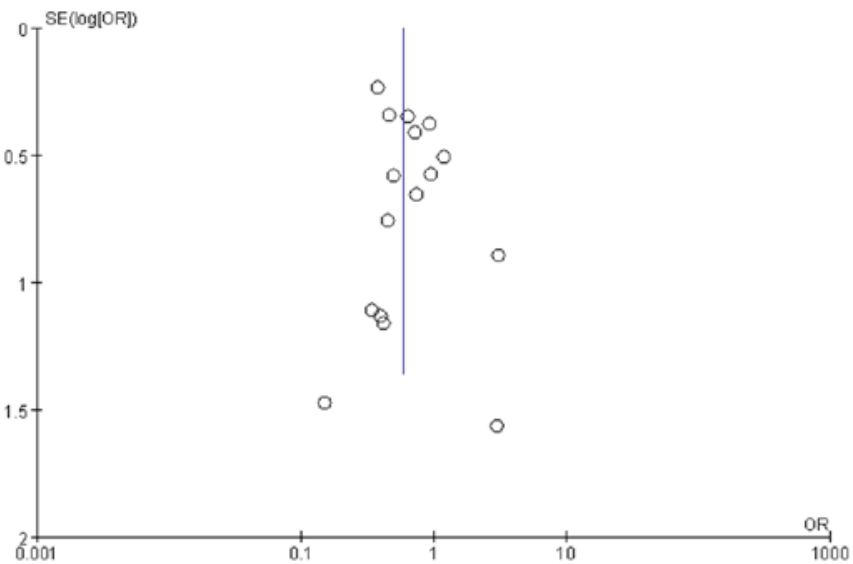

Figure 8. Funnel plot showing the 1- year OS rates of patients that had undergone RFA or RES procedures indicates symmetry, suggesting that there was no serious publication bias. OS, overall survival; RFA, radiofrequency ablation; RES, surgical resection.

ORs of the 3- and 5-year DFS rates between the two groups were $0.418(95 \% \mathrm{CI}, 0.267-0.653 ; \mathrm{P}<0.001)$ and 0.374 (95\% CI, 0.231-0.606; P<0.001), respectively (Figs. 6 and 7).

\section{Subgroup analysis}

Subgroup of mean tumor size $\leq 3 \mathrm{~cm}$. The 3- and 5-year OS rates and the 1-, 3- and 5-year DFS rates of the RES group of patients with HCC were significantly higher than those of the RFA group. The 1-year OS rate of patients in the RES group was not significantly higher than that of the RFA group.

Subgroup of mean tumor size $>3 \mathrm{~cm}$. The 5-year OS rates and the 1- and 3-year DFS rates of patients treated with RES were significantly different than the RFA treatment group, whereas the 1- and 3-year OS rates and the 5-year DFS rate of patients treated with RES were not significantly higher than those of the RFA treatment group.

Testing for publication bias. A funnel plot was used to determine the level of bias (Fig. 8). The funnel plot for 1-year OS rates following RFA or RES shows symmetry, which suggests that there was no signficant publication bias. In addition, Begg tests were performed to exclude the possibility of asymmetry

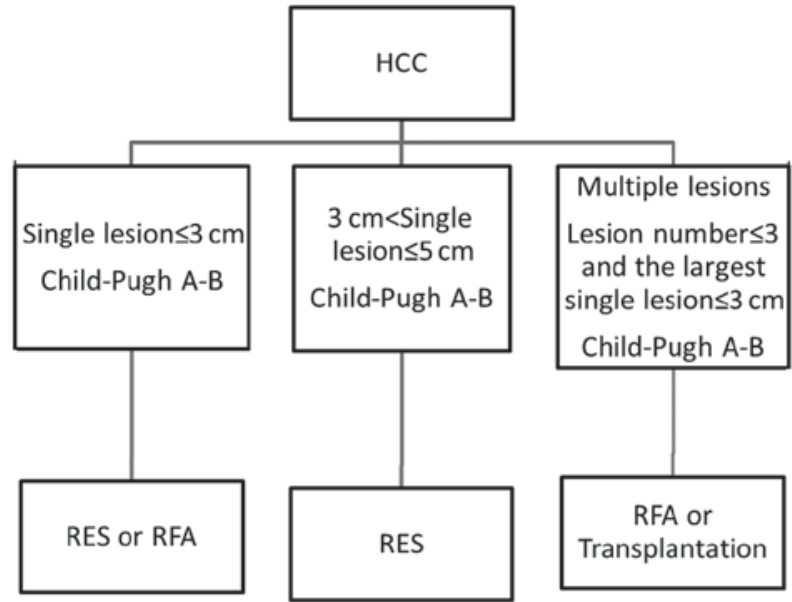

Figure 9. Flow-chart of recommended therapeutic regime for patients with small HCC. HCC, hepatocellular carcinoma; RES, surgical resection; RFA, radiofrequency ablation.

in funnel plots (continuity corrected, $\mathrm{z}=1.35, \mathrm{P}=0.178$ ). The results of the Begg tests suggested that chances of publication bias were minimal.

\section{Discussion}

At present, RES and RFA are commonly used and regarded as the curative methods for the treatment of patients with small HCC tumors. However, no definite consensus for which modality is the most effective has been reached. OS and DFS are two common primary indexes used to assess the curative effects of treatments for patients with cancer. Each index emphasizes different factors. DFS is a significant index that reveals the treatment effect of therapeutic modalities employed, while OS represents the response to the overall condition, including comprehensive treatment modalities, the state of patient health, and other relevant factors that influence survival. Although DFS is considered to be the more appropriate index for evaluating the effect of the therapeutic modalities used, in accordance with current practice, both DFS and OS rates were used to compare the therapeutic effectiveness of RES and RFA in the current study. The results of the meta-analysis 
demonstrated that RES was superior to RFA with regards to the survival of patients with resectable HCC. This is because the 1-, 3- and 5-year OS and DFS rates of patients treated using RFA were generally lower than those treated with RES. RFA techniques use thermal effects to kill tumor cells (42-44). The ablation process is influenced by numerous factors, such as overall energy deposition, the duration of application, electrode types or tip length and gauge. In addition, if ablation is applied with or without pulsed radiofrequency or cluster techniques, this may result in instability of the required RFA therapy effect (45-47), and may lead to higher recurrence rates. By contrast, RES has been demonstrated to eliminate cancer nodules thoroughly and prevent recurrence $(32,48,49)$. Therefore, the OS and DFS rates of patients treated using RFA are lower than that of RES. Mulier et al (50) concluded that the short-term benefits of using a less invasive method through the percutaneous route of RFA does not counteract the increased long-term risk of local recurrence (Belgium and Netherlands). Therefore, the authors of the present study consider that RES may serve an important role in the treatment of patients with HCC (8). As such, clinicians treating HCC patients within the Milan criteria should consider hepatectomy as the primary treatment option if the patient's liver function and general condition are sufficient for surgery (51) (Korea).

At present, RFA is frequently used as a first-line treatment option for patients with HCC tumors as large as $5 \mathrm{~cm}$ (52). It is generally considered that the smaller the lesion, the better the effect of treatment. Peng et al (41) demonstrated that the OS rates, but not the recurrence-free survival rates, of percutaneous RFA were significantly improved when compared with those of RES in patients with HCC tumors measuring $\leq 2 \mathrm{~cm}$. In addition, subgroup analysis of patients with central HCC (where the tumor is located $>3 \mathrm{~cm}$ from the liver capsule), the OS and recurrence-free survival rates of percutaneous RFA were improved when compared with RES (China). This previous study provided an explanation for the superior effect of RFA when compared with RES. However, it did not provide an explanation for the worse relative efficacy of RES, aside from the observation that patients treated using this method had more severe complications. The conclusions of this previous study contradicted the majority of other relevant studies $(18,30,31,53)$. Guo et al collated and performed a meta-analysis of previous studies to assess the outcomes of combined transcatheter arterial chemoemobolization (TACE)-RFA vs. RES alone in patients with early HCC and small resectable tumors. The results demonstrated that, even though TACE-RFA showed comparable 1- and 3-year OS rates and 1-year recurrence-free rates compared with RES, this combination was associated with significantly lower 3-year recurrence-free survival rates compared with RES. Therefore, the authors concluded that RES should still be considered as the primary choice of treatment for patients with early HCC (54).

In the present study, subgroup analysis was performed to better compare the outcomes of RES and RFA in patients with HCC. To achieve this, patients were divided into two subgroups based on mean tumor size $(\sim 3 \mathrm{~cm})$. In the group of patients with tumors $\leq 3 \mathrm{~cm}$ in size, those treated with RES demonstrated significantly improved 3- and 5-year OS rates, as well as 1-, 3- and 5-year DFS rates, compared with those treated with RFA. It was therefore considered that if patients are in good physical condition and have good liver function, treatment using RES may likely increase their OS. In the group of patients with a mean tumor size of $>3 \mathrm{~cm}$, those treated using RES demonstrated significantly higher 5-year OS rates and 1- and 3-year DFS rates compared to those treated using RFA; however, no significant difference between the 1- and 3-year OS rates, and the 5-year DFS rates was observed between these groups. Based on the results of the present study, the authors recommend a therapeutic regimen for patients with small HCC tumors, as presented in the flow-chart (Fig. 9).

In current studies, local intrahepatic recurrences were found to be more frequent following RFA when compared with RES. Local recurrences following RFA may be attributable to insufficient ablation of the primary tumor and/or the presence of tumor venous invasion in the adjacent liver tissue. By contrast, RES may remove the primary tumor and venous tumor thrombi (32) which may explain the improved survival rates following RES.

An ideal meta-analysis should include individual patient data. However, these data are not always available or may be impractical to collect. Therefore, the majority of meta-analyses, including the current study, are instead performed using summary data, which is an accepted form of analysis. However, in the present study, it was not possible to perform a complete analysis of the causes of death in the selected studies due to the lack of individual patient data. Another limitation of the current study was that numerous observational studies included in the analysis had significant heterogeneity due to the nature of the surgical studies. Specifically, it is difficult to perform the same operations across different hospitals. Therefore, the outcomes of the RES procedure across different centers may be, to some extent, not comparable. In addition, bias caused by a number of different factors, such as case selection, patient condition, medical equipment and the individual dependence of surgical techniques may affect statistical analysis of the results. In order to perform more rigorous testing, a random-effects model was used for the meta-analysis. The inclusion of a limited number of RCTs from original published studies is another important limitation of the current study, and meta-analyses have been traditionally applied and are best confined to RCTs. However, it has also been demonstrated that meta-analytical techniques using non-RCT and observational studies may present a valid method in some clinical settings, where either the number or the sample size of RCTs is insufficient (55) (France).

In conclusion, this meta-analysis of studies compared the long-time survival rates of RFA and RES techniques for the treatment of patients with HCC. RES was demonstrated to show superior 1-, 3- and 5-year OS and DFS rates than RFA for patients with small HCC that were eligible for surgical treatment. However, RFA can be an alternative therapeutic option for patients with small single HCC tumors that are not suitable for RES. Future RCTs are required to clarify the value of RES and RFA for the treatment of patients with HCC.

\section{Acknowledgements}

The authors would like to thank Professor Jinshan Zhang, the former director of Radiology department of Chinese PLA General Hospital, for his permission to perform the current 
study, and for providing necessary consultation on radiofrequency ablation techniques.

\section{Funding}

The present study was supported by Sanya Meical Science and Technical Innovation Funding (grant no. 2017YW02).

\section{Availability of data and materials}

The datasets used and/or analyzed during the current study are available from the corresponding author on reasonable request.

\section{Authors' contributions}

JKL designed the current study and interpreted the results. XHL retrieved the literature and wrote the manuscript. HC interpreted and analyzed the data. XHX performed the statistical analysis. All authors read and approved the final manuscript.

\section{Ethics approval and consent to participate}

Not applicable.

\section{Patient consent for publication}

Not applicable.

\section{Competing interests}

The authors declare that they have no competing interests.

\section{References}

1. Bosch FX, Ribes J and Borras J: Epidemiology of primary liver cancer. Semin Liver Dis 19: 271-285, 1999.

2. El-Serag HB and Rudolph KL: Hepatocellular carcinoma: Epidemiology and molecular carcinogenesis. Gastroenterology 132: 2557-2576, 2007.

3. Taylor-Robinson SD, Foster GR, Arora S, Hargreaves S and Thomas HC: Increase in primary liver cancer in the UK, 1979-94. Lancet 350: 1142-1143, 1997.

4. El-Serag HB and Mason AC: Rising incidence of hepatocellular carcinoma in the United States. N Engl J Med 340: 745-750, 1999.

5. Malago M, Rogiers X and Broelsch CE: Liver splitting and living donor techniques. Br Med Bull 53: 860-867, 1997.

6. Ryder SD and British Society of Gastroenterology: Guidelines for the diagnosis and treatment of hepatocellular carcinoma (HCC) in adults. Gut 52(Suppl 3): iii1-iii8, 2003.

7. Johnson PJ: Hepatocellular carcinoma: Is current therapy really altering outcome? Gut 51: 459-462, 2002.

8. Bruix $\mathbf{J}$ and Llovet JM: Prognostic prediction and treatment strategy in hepatocellular carcinoma. Hepatology 35: 519-524, 2002.

9. Bruix J, Sherman M, Llovet JM, Beaugrand M, Lencioni R, Burroughs AK, Christensen E, Pagliaro L, Colombo M and Rodés J; EASL Panel of Experts on HCC: Clinical management of hepatocellular carcinoma. Conclusions of the Barcelona-2000 EASL conference. European Association for the Study of the Liver. J Hepatol 35: 421-430, 2001.

10. Livraghi T: Guidelines for treatment of liver cancer. Eur J Ultrasound 13: 167-176, 2001.

11. Lai EC, Fan ST, Lo CM, Chu KM, Liu CL and Wong J: Hepatic resection for hepatocellular carcinoma. An audit of 343 patients. Ann Surg 221: 291-298, 1995.

12. Marin-Hargreaves G, Azoulay D and Bismuth H: Hepatocellular carcinoma: Surgical indications and results. Crit Rev Oncol Hematol 47: 13-27, 2003.
13. Arii S, Yamaoka Y, Futagawa S, Inoue K, Kobayashi K, Kojiro M, Makuuchi M, Nakamura Y, Okita K and Yamada R: Results of surgical and nonsurgical treatment for small-sized hepatocellular carcinomas: A retrospective and nationwide survey in Japan. The Liver Cancer Study Group of Japan. Hepatology 32: 1224-1229, 2000.

14. Fried MW: Treatment of hepatocellular carcinoma: Medical options. Liver Transpl Surg 4 (5 Suppl 1): S92-S97, 1998.

15. Ogihara M, Wong LL and Machi J: Radiofrequency ablation versus surgical resection for single nodule hepatocellular carcinoma: Long-term outcomes. HPB (Oxford) 7: 214-221, 2005.

16. Ogata S, Belghiti J, Varma D, Sommacale D, Maeda A, Dondero F and Sauvanet A: Two hundred liver hanging maneuvers for major hepatectomy: A single-center experience. Ann Surg 245: 31-35, 2007.

17. Li L, Zhang J, Liu X, Li X, Jiao B and Kang T: Clinical outcomes of radiofrequency ablation and surgical resection for small hepatocellular carcinoma: A meta-analysis. J Gastroenterol Hepatol 27: 51-58, 2012.

18. Ng KKC, Chok KSH, Chan ACY, Cheung TT, Wong TCL, Fung JYY, Yuen J, Poon RTP, Fan ST and Lo CM: Randomized clinical trial of hepatic resection versus radiofrequency ablation for early-stage hepatocellular carcinoma. Br J Surg 104: 1755-1784, 2017.

19. Machi J, Uchida S, Sumida K, Limm WM, Hundahl SA, Oishi AJ, Furumoto NL and Oishi RH: Ultrasound-guided radiofrequency thermal ablation of liver tumors: Percutaneous, laparoscopic, and open surgical approaches. J Gastrointest Surg 5: 477-489, 2001.

20. Poon RT, Fan ST, Tsang FH and Wong J: Locoregional therapies for hepatocellular carcinoma: A critical review from the surgeon's perspective. Ann Surg 235: 466-486, 2002.

21. Chen MS, Li JQ, Zheng Y, Guo RP, Liang HH, Zhang YQ, Lin XJ and Lau WY: A prospective randomized trial comparing percutaneous local ablative therapy and partial hepatectomy for small hepatocellular carcinoma. Ann Surg 243: 321-328, 2006.

22. Huang J, Yan L, Cheng Z, Wu H, Du L, Wang J, Xu Y and Zeng Y: A randomized trial comparing radiofrequency ablation and surgical resection for $\mathrm{HCC}$ conforming to the Milan criteria. Ann Surg 252: 903-912, 2010.

23. Feng K, Yan J, Li X, Xia F, Ma K, Wang S, Bie P and Dong J: A randomized controlled trial of radiofrequency ablation and surgical resection in the treatment of small hepatocellular carcinoma. J Hepatol 57: 794-802, 2012.

24. Hong SN, Lee SY, Choi MS, Lee JH, Koh KC, Paik SW, Yoo BC, Rhee JC, Choi D, Lim HK, et al: Comparing the outcomes of radiofrequency ablation and surgery in patients with a single small hepatocellular carcinoma and well-preserved hepatic function. J Clin Gastroenterol 39: 247-252, 2005.

25. Montorsi M, Santambrogio R, Bianchi P, Donadon M, Moroni E, Spinelli A and Costa M: Survival and recurrences after hepatic resection or radiofrequency for hepatocellular carcinoma in cirrhotic patients: A multivariate analysis. J Gastrointest Surg 9: 62-67; discussion 67-68, 2005.

26. Nishikawa H, Inuzuka T, Takeda H, Nakajima J, Matsuda F, Sakamoto A, Henmi S, Hatamaru K, Ishikawa T, Saito S, et al: Comparison of percutaneous radiofrequency thermal ablation and surgical resection for small hepatocellular carcinoma. BMC Gastroenterol 11: 143, 2011

27. Vivarelli M, Guglielmi A, Ruzzenente A, Cucchetti A, Bellusci R, Cordiano C and Cavallari A: Surgical resection versus percutaneous radiofrequency ablation in the treatment of hepatocellular carcinoma on cirrhotic liver. Ann Surg 240: 102-107, 2004.

28. Xu G, Qi FZ, Zhang JH, Cheng GF, Cai Y and Miao Y: Meta-analysis of surgical resection and radiofrequency ablation for early hepatocellular carcinoma. World J Surg Oncol 10: 163, 2012.

29. Livraghi T, Meloni F, Di Stasi M, Rolle E, Solbiati L, Tinelli C and Rossi S: Sustained complete response and complications rates after radiofrequency ablation of very early hepatocellular carcinoma in cirrhosis: Is resection still the treatment of choice? Hepatology 47: 82-89, 2008.

30. Tashiro H, Aikata H, Waki K, Amano H, Oshita A, Kobayashi T, Tanimoto Y, Kuroda S, Tazawa H, Chayama K, et al: Treatment strategy for early hepatocellular carcinomas: Comparison of radiofrequency ablation with or without transcatheter arterial chemoembolization and surgical resection. J Surg Oncol 104: 3-9, 2011. 
31. Abu-Hilal M, Primrose JN, Casaril A, McPhail MJ, Pearce NW and Nicoli N: Surgical resection versus radiofrequency ablation in the treatment of small unifocal hepatocellular carcinoma. J Gastrointest Surg 12: 1521-1526, 2008.

32. Liu JG, Wang YJ and Du Z: Radiofrequency ablation in the treatment of small hepatocellular carcinoma: A meta analysis. World J Gastroenterol 16: 3450-3456, 2010.

33. Cho YK, Rhim H and Noh S: Radiofrequency ablation versus surgical resection as primary treatment of hepatocellular carcinoma meeting the Milan criteria: A systematic review. J Gastroenterol Hepatol 26: 1354-1360, 2011.

34. Zhou Y, Zhao Y, Li B and Xu D: Meta-analysis of radiofrequency ablation versus hepatic resection for small hepatocellular carcinoma. BMC Gastroenterol 10: 78, 2010.

35. Xu XL, Liu XD, Liang $M$ and Luo BM: Radiofrequency ablation versus hepatic resection for small hepatacellular carcinoma: Systematic review of randomized controlled trials with meta-analysis and trial sequential analysis. Radiology 287 461-472, 2018.

36. Jadad AR, Moore RA, Carroll D, Jenkinson C, Reynolds DJ, Gavaghan DJ and McQuay HJ: Assessing the quality of reports of randomized clinical trials: Is blinding necessary? Control Clin Trials 17: 1-12, 1996.

37. Wells G, Shea B, O'Connell D, Peterson J, Welch V, Losos M and Tugwell P: The Newcastle-Ottawa Scale (NOS) for assessing the quality of nonrandomised studies in meta-analyses. Available at: http://www.evidencebasedpublichealth.de/download/Newcastle_ Ottowa_Scale_Pope_Bruce.pdf.

38. Borenstein M,Hedges L, Higgins JPT and Rothstein H: Fixed effect vs. random effects. In: Introduction to Meta-Analysis. John Wiley and Sons Ltd., Chichester, UK, 2009.

39. Yakoub D, Athanasiou T, Tekkis P and Hanna GB: Laparoscopic assisted distal gastrectomy for early gastric cancer: Is it an alternative to the open approach? Surg Oncol 18: 322-333, 2009

40. Huang J, Hernandez-Alejandro R, Croome KP, Yan L, Wu H, Chen Z, Prasoon P and Zeng Y: Radiofrequency ablation versus surgical resection for hepatocellular carcinoma in Childs A cirrhotics-a retrospective study of 1,061 cases. J Gastrointest Surg 15: 311-320, 2011.

41. Peng ZW, Lin XJ, Zhang YJ, Liang HH, Guo RP, Shi M and Chen MS: Radiofrequency ablation versus hepatic resection for the treatment of hepatocellular carcinomas $2 \mathrm{~cm}$ or smaller: A retrospective comparative study. Radiology 262: 1022-1033, 2012.

42. Sironi S, Livraghi T, Meloni F, De Cobelli F, Ferrero C and Del Maschio A: Small hepatocellular carcinoma treated with percutaneous RF ablation: MR imaging follow-up. AJR Am J Roentgenol 173: 1225-1229, 1999.

43. Livraghi T, Goldberg SN, Lazzaroni S, Meloni F, Ierace T, Solbiati L and Gazelle GS: Hepatocellular carcinoma: Radio-frequency ablation of medium and large lesions. Radiology 214: 761-768, 2000.

44. Livraghi T, Solbiati L, Meloni MF, Gazelle GS, Halpern EF and Goldberg SN: Treatment of focal liver tumors with percutaneous radio-frequency ablation: Complications encountered in a multicenter study. Radiology 226: 441-451, 2003.
45. Goldberg SN and Gazelle GS: Radiofrequency tissue ablation: Physical principles and techniques for increasing coagulation necrosis. Hepatogastroenterology 48: 359-367, 2001.

46. Miao Y, Ni Y, Yu J and Marchal G: A comparative study on validation of a novel cooled-wet electrode for radiofrequency liver ablation. Invest Radiol 35: 438-444, 2000.

47. Goldberg SN, Gazelle GS, Solbiati L, Rittman WJ and Mueller PR: Radiofrequency tissue ablation: Increased lesion diameter with a perfusion electrode. Acad Radiol 3: 636-644, 1996.

48. Sasaki A, Kai S, Iwashita Y, Hirano S, Ohta M and Kitano S: Microsatellite distribution and indication for locoregional therapy in small hepatocellular carcinoma. Cancer 103: 299-306, 2005.

49. Shiina S, Tagawa K, Unuma T, Takanashi R, Yoshiura K, Komatsu Y, Hata Y, Niwa Y, Shiratori Y and Terano A: Percutaneous ethanol injection therapy for hepatocellular carcinoma. A histopathologic study. Cancer 68: 1524-1530, 1991.

50. Mulier S, Ni Y, Jamart J, Ruers T, Marchal G and Michel L: Local recurrence after hepatic radiofrequency coagulation: Multivariate meta-analysis and review of contributing factors. Ann Surg 242: 158-171, 2005.

51. Park EK, Kim HJ, Kim CY, Hur YH, Koh YS, Kim JC, Kim HJ, Kim JW and Cho CK: A comparison surgical resection and radiofrequency ablation in the treatment of hepatocellular carcinoma. Ann Surg Treat Res 87: 72-80, 2014.

52. Kutlu OC, Chan JA, Aloia TA, Chun YS, Kaseb AO, Passot G, Yamashita S, Vauthey JN and Conrad C: Comparative effectiveness of first-line radiofrequency ablation versus surgical resection and transplantation for patents with early hepatocellular carcinoma. Cancer 123: 1817-1827, 2017.

53. Gravante G, Overton J, Sorge R, Bhardwaj N, Metcalfe MS, Lloyd DM and Dennison AR: Radiofrequency ablation versus resection for liver tumors: An evidence-based approach to retrospective compartive studies. J Gastrointest Surg 15: 378-387, 2011.

54. Guo W, He X, Li Z and Li Y: Combination of transarterial chemoembolization (TACE) and radiofrequency ablation (RFA) vs. Surgical resection (SR) on survival outcome of early hepatocellular carcinoma: A meta-analysis. Hepatogastroenterology 62: 710-714, 2015

55. Mathurin P, Raynard B, Dharancy S, Kirzin S, Fallik D, Pruvot FR, Roumilhac D, Canva V, Paris JC, Chaput JC and Naveau S: Meta-analysis: Evaluation of adjuvant therapy after curative liver resection for hepatocellular carcinoma. Aliment Pharmacol Ther 17: 1247-1261, 2003.

This work is licensed under a Creative Commons Attribution-NonCommercial-NoDerivatives 4.0 International (CC BY-NC-ND 4.0) License. 